\title{
Relationship of Uric Acid with Superoxide Dismutase (Sod) in Induced Hyperuricemic Rat Model
}

\author{
Shiza Batool ${ }^{1}$, Iftikhar Ahmed ${ }^{2 *}$, Muhammad Sarwar ${ }^{3}$, Hafeez ul Hassan ${ }^{4}$ \\ ${ }^{1}$ Biochemistry Department, Aziz Fatima Medical and Dental College, Faisalabad, Pakistan; ${ }^{2}$ Biochemistry Department, Baqai Medi- \\ cal University, Karachi, Pakistan; ${ }^{3}$ Chemical Pathology Department, Al Jouf University, Al-Jawf, KSA; ${ }^{4}$ Physiology Department, \\ Baqai Medical University, Karachi, Pakistan. \\ Email: "dr_iftikharahmed@yahoo.com, "driftikharahmed68@gmail.com
}

Received July $16^{\text {th }}, 2012$; revised August $18^{\text {th }}, 2012$; accepted September $12^{\text {th }}, 2012$

\begin{abstract}
Increase uric acid levels have been found in oxidative stress. Urate radicals do not react with oxygen to form another peroxy radical, thus increasing the efficacy of uric acid as an antioxidant. Therefore, this study is designed to measure the level of uric acids and find out the relationship of uric acid with superoxide dismutase in induced hyperuricemic model. Forty male albino rats with an average weight of $180 \pm 2 \mathrm{~g}$ were selected. The rats were grouped. The animals were fed on standard diet and given tap water ad libitum until treatment. Albino rats were divided into four groups. Group A (10) — control given only standard diet, group B (10) fed on 60\% fructose with standard diet, group C (10) fed on fructose, standard diet and intraperitonially oxonic acid $250 \mathrm{mg} / \mathrm{kg}$ and group D (10) only on injection intraperotonially oxonic acid $250 \mathrm{mg} / \mathrm{kg}$. At the end of study $10 \mathrm{~mL}$ of blood was drawn from heart of rats. Then blood was estimated for superoxide dismutase and uric acids done by kit methods randox-manual/Rx monza UA230/UA 233. Results: In Group C superoxide dismutase was found to be $32 \%(244 \pm 2.23 \mathrm{mg} / \mathrm{dL})$ more than control. In the same group the uric acid concentration was highly significantly correlated with control. Conclusion: The uric acid concentration increases when we take fructose up to $60 \%$ in our diet. It also increases superoxide dismutase concentration. More than this value may have inverse effect on the uric acid level and its role as an antioxidant may become inversed.
\end{abstract}

Keywords: Uric Acid; Superoxide Dismutase; Albino Rats; Fructose Induced Hyperuricemia

\section{Introduction}

Free radical can be defined as any molecular species capable of independent existence that contains an unpaired electron in an atomic orbital [1]. They are capable of triggering chain reactions which can damage the different cell constituents.

The most important free radicals in many disease states are oxygen derivatives, particularly superoxide and the hydroxyl radical. Superoxide is formed from several molecules by oxidation including adrenaline, flavine nucleotides, thiol compounds and glucose. Superoxide is also produce during important biological reactions including electron transport chain in mitochondria [2].

In order to check free radicals formation to avoid oxidative stress, body has different anti-oxidant defense systems. An antioxidant can be defined as: "any substance that when present in low concentrations compared to that of an oxidisable substrate significantly delays or inhibits the oxidation of that substrate. The physiological role of antioxidants, as this definition suggests, is to pre-

\footnotetext{
*Corresponding author.
}

vent damage to cellular components arising as a consequence of chemical reactions involving free radicals [3]. Superoxide dismutase is believed to serve as first line of defense against toxicity of superoxide radicals. Also takes part in cell signaling regarding to reactive oxygen species levels [4]. Superoxide is one of the main reactive oxygen species in the cell and as such, SOD serves a key antioxidant role. The physiological importance of SODs is illustrated by the severe pathologies evident in mice genetically engineered to lack these enzymes. Mice lacking SOD2 die several days after birth, amid massive oxidative stress [5] Mice lacking SOD1 develop a wide range of pathologies, including hepatocellular carcinoma [6] an acceleration of age-related muscle mass loss [7], an earlier incidence of cataracts and a reduced lifespan. Mice lacking SOD3 do not show any obvious defects and exhibit a normal lifespan, though they are more sensitive to hyperoxic injury [8].

Uric acid now is not considered as merely a metabolic waste. It has been proposed that increase in life span observed in human evolution to some extent might be due to protective action of uric acid [9]. Increase uric acid 
levels have been found in oxidative stress and ischemia which might be compensatory mechanism of protection against free radicals [10]. Urate radicals do not react with oxygen to form another peroxy radical which is seen with the ascorbic acid, thus increasing the efficacy of uric acid as an antioxidant [11]. Uric acid cause inactivation of Nitric oxide and peroxynitrite radicals [12,13]. Another important function of urate is found in its ability to form chelating agents with transition metals ions like iron and copper thus scavenging them. We carried out a study to assess the relationship of uric acid with superoxide dismutase in an induced hyperuricemic rats.

\section{Methodology}

Locally bred forty (40) male Albino rats with an average weight of $180 \pm 20 \mathrm{~g}$ were purchased. The rats were grouped and housed in environmentally controlled room (ambient temperature $24^{\circ} \mathrm{C} \pm 2^{\circ} \mathrm{C}$ and relative humidity of $55 \% \pm 5 \%$ ) in the animal house and acclimatized for 07 days. The animals were fed standard diet and given tap water ad libitum until treatment. The protocols for experimentation was approved and performed in strict accordance with the Guide for the care and use of laboratory animals (Institute of Laboratory Animal Resources on Life Sciences, US National Research Council, 1996) and the Institutional Animal Ethical Committee (IAEC) of Baqai Medical University, Karachi. Pakistan. The cage size was $8 " \times 18 " \times 10^{\prime \prime}$ to keep a group of 5 animals in the cage to prevent from cannibalism.

Sodium Tungstate $10 \%$, $2 / 3 \mathrm{~N}$ sulphuric acid, $10 \%$ sodium bicarbonate, $\mathrm{LiCO}_{3}, 40 \%$ Formaline, Acetic acid, Fructose, Oxonic acid. Spectrosol grade reagents and acids from B.D.H., Poole, UK, were employed. All purified enzymes, coenzymes, substrates, standards and buffers will be purchased from Sigma Chemicals Company, USA. All other chemicals were of analytical grade and will be procured from SRL and Qualigens, USA.

All animals housed in standard conditions were initially fed standard diet and allowed adaptation of one
(1) week. Albino rats were divided in four (4) groups: A, B, C \& D.

Group A: Ten (10) male albino rats as Control were kept as control and were fed standard diet and water ad libitum for 10 weeks. Group B: Ten (10) male albino rats [F] were fed $60 \%$ fructose mixed in standard diet and water ad libitum for 10 weeks. Group C: Ten (10) male albino rats [FO] were fed $60 \%$ fructose mixed in standard diet and water ad libitum for 10 weeks. They were also injected intraperitonealy oxonic acid $250 \mathrm{mg} / \mathrm{kg}$ every third day for 10 weeks. Group D: Ten (10) male albino rats [O] were injected intraperitonealy oxonic acid 250 $\mathrm{mg} / \mathrm{kg}$ every third day for 10 weeks. They were fed standard diet and water ad libitum for 10 weeks. Body weights were measured at the commencement and at the end of study. The amount of diet was measured before giving and then subtracted from the amount of food left over daily. At the end of study, rats were dissected in a nearby room separate from experiment area. Approximately 10 mls of blood was drawn from heart using disposable syringe. $8 \mathrm{mls}$ of blood was transferred in heparinized tube, mixed and centrifuged to separate plasma and divided in two epindorf cups for estimation of uric acid and SOD done by kit methods by randox-manual /Rx monza UA230/UA 233.

\section{Results}

\subsection{Graph 1}

It demonstrates the comparison of mean plasma uric acid levels of Control with rest of the groups. Mean plasma level of uric acid of Control is found to be $1.97 \mathrm{mg} / \mathrm{dL}$ ( \pm 0.09 ). Group "F" (fructose) showed mean plasma uric acid of $3.15 \mathrm{mg} / \mathrm{dL}( \pm 0.17)$. This reflects that uric acid was raised to $37 \%$ in rats which were exposed to diet comprising 60\% Fructose than control. On comparing both groups i.e., Control with Group "F" (highly significant statistical correlation $(\mathrm{P}<0.001)$ was observed.

The mean plasma uric acid levels of Group "O”

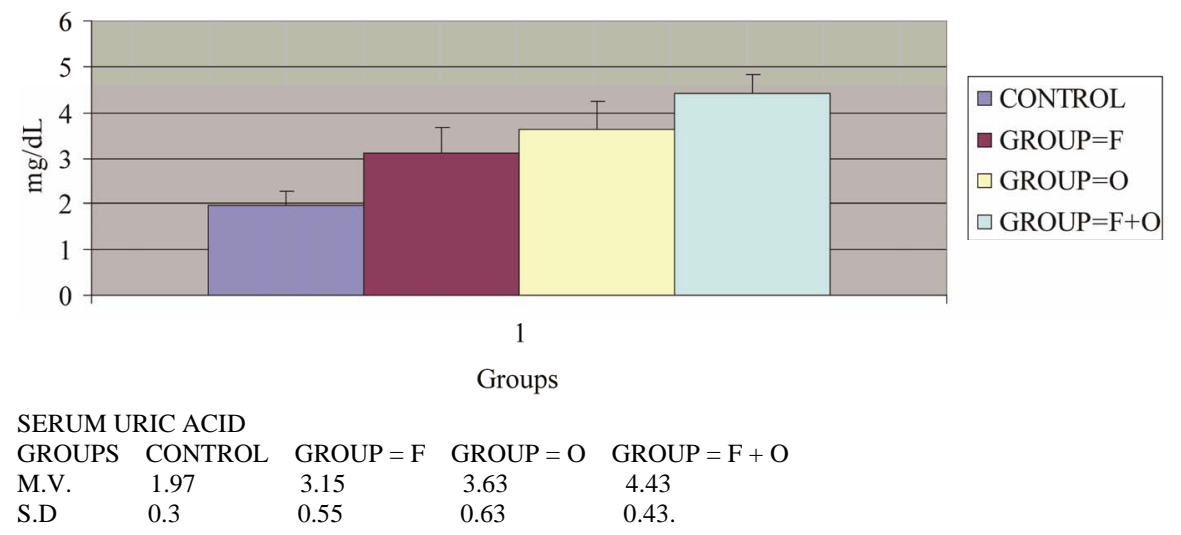

Graph 1. Comparison of serum uric acid levels of all study groups. 
(oxonic acid) was $3.63 \mathrm{mg} / \mathrm{dL}( \pm 0.22)$ which is $45 \%$ higher than Control. The probability calculated was highly significant $(\mathrm{P}<0.001)$ when both groups were evaluated.

While comparing Group "F + O" (Fructose + Oxonic acid) with Control, highly significant correlation was observed $(\mathrm{P}<0.001)$. It was due to high mean plasma serum uric acid level of Group " $\mathrm{F}+\mathrm{O}$ " which was 4.41 $\mathrm{mg} / \mathrm{dL}( \pm 0.14)$. The combination of fructose with uricase inhibitor, Oxonic acid raises uric acid to 55\% from control and this level is highest of all these groups.

\subsection{Graph 2}

It shows the comparison of mean plasma SOD levels of Control with rest of the groups. Mean plasma level of SOD of Control was found to be $165.15 \mathrm{mg} / \mathrm{dL}( \pm 2.65)$. Group "F" (Fructose) showed mean plasma SOD level of $176.65 \mathrm{mg} / \mathrm{dL}( \pm 2.60)$ reflecting SOD levels were raised to $6.5 \%$ in rats which were exposed to diet comprising $60 \%$ Fructose. On comparing both groups i.e., Control with Group "F" significant statistical correlation $(\mathrm{P}<$ $0.01)$ was observed. The mean plasma SOD levels of Group "O" (oxonic acid) has been measured to 181.2 $\mathrm{mg} / \mathrm{dL}( \pm 3.52)$ which is again $8 \%$ more than Control. Therefore, significant $(\mathrm{P}<0.01)$ correlation was observed on comparison of both groups.

While comparing Group " $\mathrm{F}+\mathrm{O}$ ” (Fructose + Oxonic acid) with Control, highly significant correlation was observed ( $\mathrm{P}<0.001)$. It was due to high mean plasma SOD levels of Group "F + O" which was $244 \mathrm{mg} / \mathrm{dL}$ $( \pm 2.23)$ which is highest of all these groups. In this group SOD was 32\% more than control which might be due to antioxidant action of uric acid.

\section{Discussion}

One of the important features of this study was the method by which hyperuricemia have been induced in animal model. The group B was given fructose, group D was treated with "oxonic acid" and group C was offered both fructose and oxonic acid ( $\mathrm{G}=$ Fructose + Oxonic acid). The principle hyperuricemic factor in this study was fructose as it is extensively used in beverages and food. Its a rather controversial factor as number of studies both animals and human, are in the favour that fructose can induce hyperuricemia [14] but many studies have opposed this hypothesis [15] and even mixed response has been shown [16]. Present investigation has tried to verify this theory. Very few studies have used this combined model of fructose plus oxonic acid. In order to make conditions similar to human, uricase inhibitor oxonic acid was incorporated to abolish the effect of this enzyme in rats. Also these different regimens were used to establish the extent of hyperuricemia caused by fructose.

Superoxide dismutase levels were found to be raised in all three groups in comparison to control. The highest level was observed in group C of $244 \mathrm{mg} / \mathrm{dL}$ as shown in graph 1 . They were $32 \%$ more than the control. This was in agreement with $\mathrm{H}$. Ulrich Hink and Nalini Santanam et al. The possible explanation can be drawn from number of studies showing that superoxide dismutase during catalyzing dismutation of $\mathrm{O}_{2}^{-}$to $\mathrm{H}_{2} \mathrm{O}_{2}$ can form copper bound hydroxyl radical from hydrogen peroxide $\mathrm{H}_{2} \mathrm{O}_{2}$ [17]. Hydroxyl radical when gets bounded to SOD, then it can attack adjacent histidine residue which is attached to copper resulting in inactivation of both SOD1 and SOD3 [18]. This might be prevented when small anions or reductants including Uric acid are co incubated [19] as shown in graph 1 the comparison of mean plasma SOD levels of Control with rest of the groups. Mean plasma level of SOD of Control was found to be $165.15 \mathrm{mg} / \mathrm{dL}$ ( \pm 2.65 ). Group B (Fructose) showed mean plasma SOD level of $176.65 \mathrm{mg} / \mathrm{dL}( \pm 2.60)$ reflecting SOD levels were raised to $6.5 \%$ in rats which were exposed to diet comprising $60 \%$ Fructose. On comparing both groups, i.e. Control with Group B significant statistical correlation $(\mathrm{P}<$ 0.01 ) was observed.
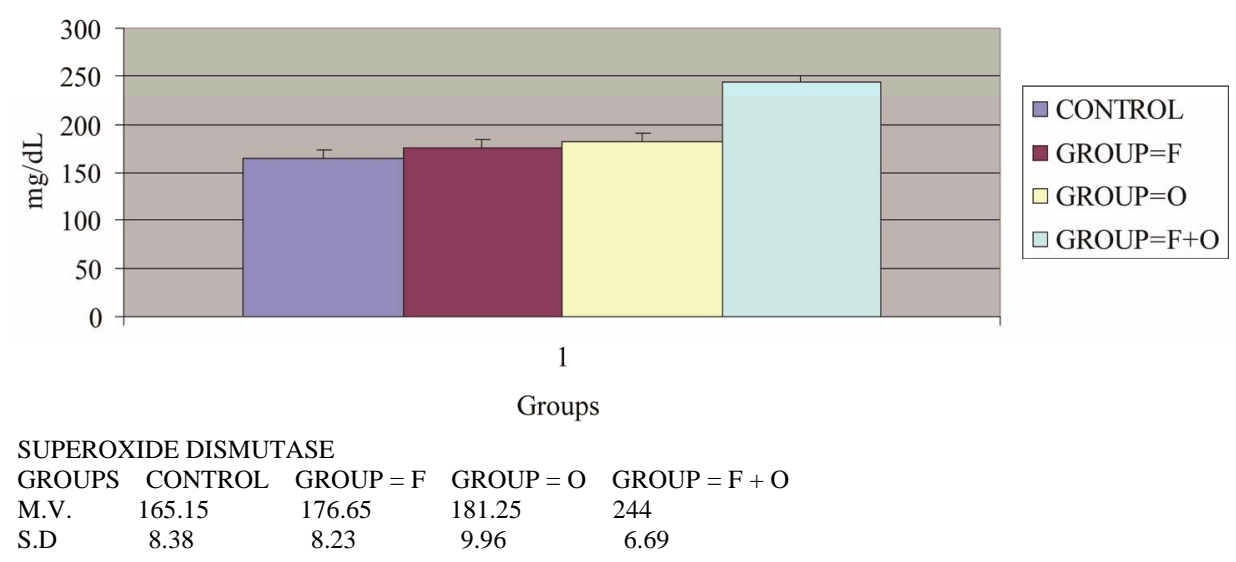

Graph 2. Comparison of serum SOD levels of all study groups. 
The mean plasma SOD levels of Group D (oxonic acid) has been measured to $181.2 \mathrm{mg} / \mathrm{dL}( \pm 3.52)$ which is again 8\% more than Control. Therefore, significant $(\mathrm{P}<$ 0.01 ) correlation was observed on comparison of both groups.

While comparing Group C (Fructose + Oxonic acid) with Control, highly significant correlation was observed ( $\mathrm{P}<0.001)$. It was due to high mean plasma SOD levels of Group "F + O" which was $244 \mathrm{mg} / \mathrm{dL}( \pm 2.23)$ which is highest of all these groups. In this group SOD was $32 \%$ more than control which might be due to antioxidant action of uric acid.

It has been suggested that in group $C$ there was significant increase in the concentration of uric acid. This was in accordance with some studies done on human that high dietary intake of fructose contributes significantly to hyperuricemia [20]. In a large study in the United States, consumption of four or more sugar-sweetened soft drinks per day gave an odds ratio of 1.82 for hyperuricemia [21]. Increased production of uric acid is the result of interference, by a product of fructose metabolism, in purine metabolism. This interference has a dual action, both increasing the conversion of ATP to inosine and increasing the synthesis of purine [22] http://en.wikipedia.org/wiki/ Hyperuricemia-cite_note-pmid8213607-14. Fructose also inhibits the excretion of uric acid, apparently by competing with uric acid for access to the transport protein SLC2A9 [23]. The effect of fructose in reducing excretion of uric acid is increased in people with a hereditary (genetic) predisposition toward hyperuricemia and/or gout [22].

Starvation causes the body to metabolize its own (purine-rich) tissues for energy. Thus, like a high purine diet, starvation increases the amount of purine converted to uric acid. A very low calorie diet without carbohydrate can induce extreme hyperuricemia; including some carbohydrate (and reducing the protein) reduces the level of hyperuricemia [24]. Starvation also impairs the ability of the kidney to excrete uric acid, due to competition for transport between uric acid and ketones [25]. Many studies are controversial to our results all were done on human some supported that high doses of fructose (200 g/day for 2 weeks) raise the blood pressure and cause the features of metabolic syndrome. Some suggested that lowering of the uric acid level prevents the increase in mean arterial blood pressure. Excessive intake of fructose may have a role in the current epidemics of obesity and diabetes [26]. Some authors also suggested that increased dietary fructose was not associated with increase uric acid level [27].

\section{Conclusion}

The uric acid concentration does increase when we take fructose up to $60 \%$ in our diet, e.g., beverages soft drinks.
It also increases superoxide dismutase concentration. It has been concluded that more than this value of fructose may have inverse effect on the uric acid level and its role as an antioxidant may become inversed. Therefore, it is suggested from our study that further work need to be done on the effect of fructose on uric acid levels in human.

\section{REFERENCES}

[1] B. Halliwell and J. M. C. Gutteridge, "Role of Free Radicals and Catalytic Metal Ions in Human Disease: An Overview," Methods in Enzymology, Vol. 186, 1990, pp. 1-85.

[2] L. B. Becker, T. L. Vanden Hoek, Z. H. Shao, C. Q. Li and P. T. Schumacker, "Generation of Superoxide in Cardiomyocytes during Ischemia before Reperfusion,” American Journal of Physiology, Vol. 277, No. 6, 1999, pp. H2240-H2246.

[3] I. S. Young and J. V. Woodside, “Antioxidants in Health and Disease,” Journal of Clinical Pathology, Vol. 54, No. 3, 2001, pp. 176-186.

[4] A. J. Augustin, "Was It oxidativer Stress?" Klinische Monatsblätter für Augenheilkunde, Vol. 227, No. 2, 2010, pp. 90-98. doi:10.1055/s-0029-1245125

[5] Y. Li, T. T. Huang, E. J. Carlson, S. Melov, P. C. Ursell, J. L. Olson, L. J. Noble, M. P. Yoshimura, C. Berger, P. H. Chan, D. C. Wallace and C. J. Epstein, "Dilated Cardiomyopathy and Neonatal Lethality in Mutant Mice Lacking Manganese Superoxide Dismutase,” Nature Genetics, Vol. 11, No. 4, 1995, pp. 376-377.

doi:10.1038/ng1295-376

[6] S. Elchuri, T. D. Oberley, W. Qi, R. S. Eisenstein, L. J. Roberts, H. Van Remmen, C. J. Epstein and T.-T. Huang, "CuZnSOD Deficiency Leads to Persistent and Widespread Oxidative Damage and Hepatocarcinogenesis Later in Life,” Oncogene, Vol. 24, No. 3, 2005, pp. 367- 380. doi:10.1038/sj.onc.1208207

[7] F. L. Muller, W. Song, Y. Liu, A. Chaudhuri, S. PiekeDahl, R. Strong, T.-T. Huang, C. J. Epstein, L. J. Roberts, M. Csete, J. A. Faulkner and H. Van Remmen, “Absence of CuZn Superoxide Dismutase Leads to Elevated Oxidative Stress and Acceleration of Age-Dependent Skeletal Muscle Atrophy,” Free Radical Biology \& Medicine, Vol. 40, No. 11, 2006, pp. 1993-1004.

doi:10.1016/j.freeradbiomed.2006.01.036

[8] M. L. Sentman, M. Granström, H. Jakobson, A. Reaume, S. Basu and S. L. Marklund, "Phenotypes of Mice Lacking Extracellular Superoxide Dismutase and Copper- and Zinc-Containing Superoxide Dismutase,” Journal of Biological Chemistry, Vol. 281, No. 11, 2006, pp. 6904-6909. doi:10.1074/jbc.M510764200

[9] B. N. Ames, R. Cathcart, E. Schwiers and P. Hochstein, "Uric Acid Provides an Antioxidant Defense in Humans against Oxidant- and Radical-Caused Aging and Cancer: A Hypothesis," Proceedings of the National Academy of Sciences of USA, Vol. 78, No. 11, 1981, pp. 6858-6862. doi:10.1073/pnas.78.11.6858

[10] F. J. Nieto, C. Iribarren, M. D. Gross, G. W. Comstock, R. 
G. Cutler, "Uric Acid and Serum Antioxidant Capacity: A Reaction to Atherosclerosis,” Atherosclerosis, Vol. 148, No. 1, 2000, pp. 131-139. doi:10.1016/S0021-9150(99)00214-2

[11] W. S. Waring, "Uric Acid: An Important Antioxidant in Acute Ischaemic Stroke,” QJM: An International Journal of Medicine, Vol. 95, No. 10, 2002, pp. 691-693. doi:10.1093/qjmed/95.10.691

[12] M. Whiteman, U. Kestsakul and B. Halliwell, "A Reassessment of the Peroxynitrite Scavenging Activity of Uric Acid," Annals of the New York Academy of Sciences, Vol. 962, 2002, pp. 242-259.

[13] G. Toncev, B. Milicic, S. Toncev and G. Samardzic, "HighDose Methylprednisolone Therapy in Multiple Sclerosis Increases Serum Uric Acid Levels,” Clinical Chemistry and Laboratory Medicine, Vol. 40, No. 5, 2002, pp. 505508. doi:10.1515/CCLM.2002.088

[14] R. J. Johnson, S. E. Perez-Pozo, Y. Y. Sautin, J. Manitius, L. G. Sanchez-Lozada, D. I. Feig, M. Shafiu, M. Segal, R. J. Glassock, M. Shimada, C. Roncal and T. Nakagawa, "Hypothesis: Could Excessive Fructose Intake and Uric Acid Cause Type 2 Diabetes," Endocrine Reviews, Vol. 30, No. 1, 2009, pp. 96-116. doi:10.1210/er.2008-0033

[15] P. A. Crapo and O. G. Kolterman, "The Metabolic Effects of 2-Week Fructose Feeding in Normal Subjects," American Journal of Clinical Nutrition, Vol. 39, No. 4, 1984, pp. 525-534.

[16] S. Z. Sun, B. D Flickinger, P. S. Williamson-Hughes and M. W. Empie, "Lack of Association between Dietary Fructose and Hyperuricemia Risk in Adults," Nutrition \& Metabolism, Vol. 7, No. 1, 2010, pp. 12-16. doi:10.1186/1743-7075-7-16

[17] H. U. Hink, N. Santanam, S. Dikalov, L. McCann, A. D. Nguyen, S. Parthasarathy, D. G. Harrison and T. Fukai, "Peroxidase Properties of Extracellular Superoxide Dismutase. Role of Uric Acid in Modulating in Vivo Activity," Arteriosclerosis, Thrombosis, and Vascular Biology, Vol. 22, No. 9, 2002, pp. 1506-1508. doi:10.1161/01.ATV.0000027524.86752.02
[18] S. L. Jewett, A. M. Rocklin, M. Ghanevati, J. M. Abel and J. A. Marach, "A New Look at a Time-Worn System: Oxidation of CuZn-SOD by $\mathrm{H}_{2} \mathrm{O}_{2}$," Free Radical Biology \& Medicine, Vol. 26, No. 7-8, 1999, pp. 905-918. doi:10.1016/S0891-5849(98)00274-3

[19] S. P. A. Goss, R. J. Singh and B. Kalyanaraman, "Bicarbonate Enhances the Peroxidase Activity of $\mathrm{Cu}, \mathrm{Zn}-\mathrm{Su}$ peroxide Dismutase. Role of Carbonate Anion Radical," The Journal of Biological Chemistry, Vol. 274, No. 40, 1999, pp. 28233-28239. doi:10.1074/jbc.274.40.28233

[20] A. Miller and K. Adeli, "Dietary Fructose and the Metabolic Syndrome,” Current Opinion in Gastroenterology, Vol. 24, No. 2, 2008, pp. 204-209.

[21] J. W. Choi and E. S. Ford, "Sugar Sweetened Soft Drinks, Diet Soft Drinks, and Serum Uric Acid Level: The Third National Health and Nutrition Examination Survey," Arthritis \& Rheumatism, Vol. 59, No. 1, 2008, pp. 109-116. doi:10.1002/art.23245

[22] P. A. Mayes, “Intermediary Metabolism of Fructose,” American Journal of Clinical Nutrition, Vol. 58, Suppl. 5, 1993, pp. 754S-765S.

[23] V. Vitart and I. Rudan, "SLC2A9 Is a Newly Identified Urate Transporter Influencing Serum Urate Concentration, Urate Excretion and Gout," Nature Genetics, Vol. 40, No. 4, 2008, pp. 437-442. doi:10.1038/ng.106

[24] A. N. Howard, "Historical Development, Efficacy and Safety of Very Low Calorie Diets,” International Journal of Obesity, Vol. 5, No. 3, 1981, pp. 195-208.

[25] W. Kirch and C. Von Gicycki, "Renal Function in Therapeutic Starvation,” Wiener klinische Wochenschrift, Vol. 92, No. 8, 1980, pp. 263-266.

[26] S. E. Perez Pozo, J. Schold and T. Nakagawa, "Excessive Fructose Intake Induces the Features of Metabolic Syndrome in Healthy Adult Men, Role of Uric Acid in Hypertensive Response,” International Journal of Obesity, Vol. 34, No. 3, 2010, pp. 454-461. doi:10.1038/ijo.2009.259 